\title{
Interactive comment on "Multiple remote sensing assessment of the catastrophic collapse in Langtang Valley induced by the 2015 Gorkha Earthquake" by Hiroto Nagai et al.
}

\section{Anonymous Referee \#1}

Received and published: 9 October 2016

\section{General comments}

This paper demonstrated an assessment of the sediments caused by a catastrophic avalanche, using Remote Sensing data, such as, ALOS-2, WorldView-3, ALOS World 3D, etc. The topic of this manuscript is quite interesting, because L-band (PALSAR-2) could penetrate the cloud and vegetation. in fact, catastrophic collapse (earthquake, debris flow, landslide, etc.) always seem to be associated with rain and vegetation. So, PALSAR-2 have a great potential to immediately indicate a catastrophic collapse and

Printer-friendly version

Discussion paper manuscript need more information to illustrate its conclusions. Below, I comment on the few things which I think can be improved. 


\section{Specific comments}

(1) "Introduction", in this section, introduced too many information about study site NHESSD (move it to the 2.1 section), but lack the background and innovation to this research, it can't attract the reader's interest immediately. (2) "2.1 study site", I think you'd better add a location map of study site to help to understand where is it. (3) "2.2 Synthetic aperture radar imagery", just defined normalized coherence decrease (NCD), didn't explain what is Coherence calculation and how to calculate it, in addition, you can't leave out the process and method to noises filter, it's too brief in this part. (4)" 2.4 Postevent optical imagery and DSM", the post-event DSM is very important to calculate the sediments volume, this paper just said "was produced by NTT DATA as its commercial service", obviously it's not enough, And "relative calibration/validation of this DSM and the AW3D DSM was performed and summarized in a supplementary material", i didn't find the supplementary material. (5) Is it possible to do field survey to verify the results? (6) Improve the quality of the figures

Interactive comment on Nat. Hazards Earth Syst. Sci. Discuss., doi:10.5194/nhess-2016-285, 2016. 